\title{
Visit efsumb.org to view the FUTURE EUROSON SCHOOLS
}
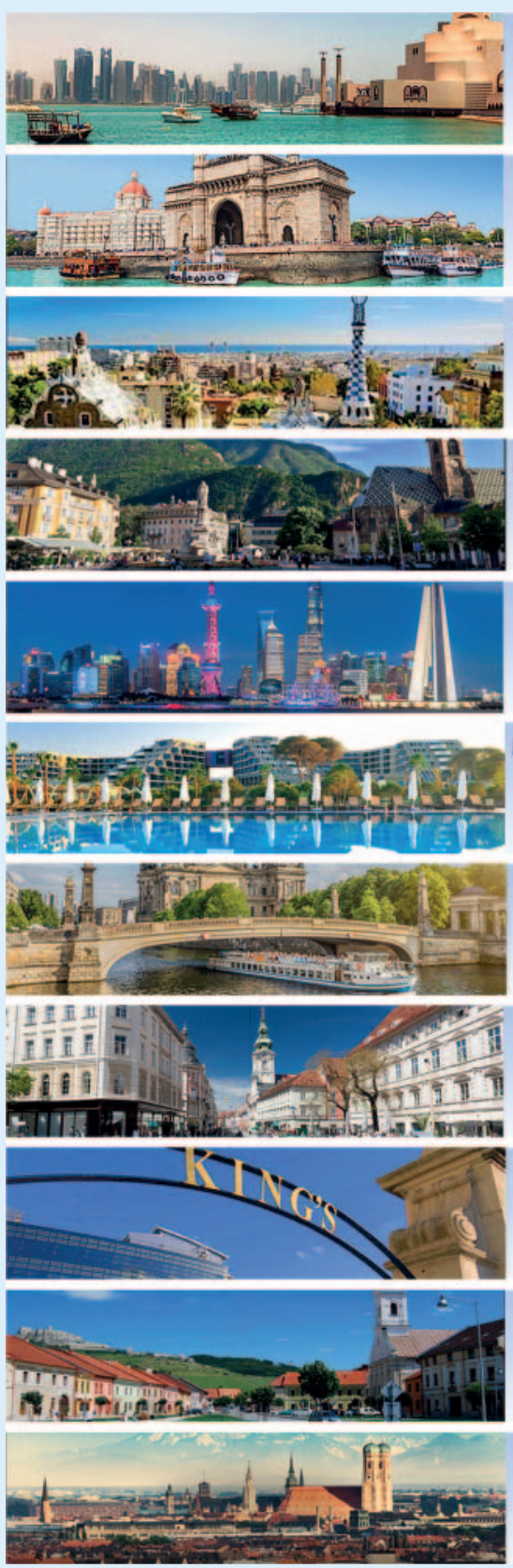

6th Qatar Musculoskeletal Ultrasound Course

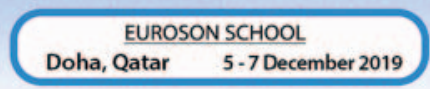

1st International Course on Intraoperative Ultrasound in Neurosurgery
EUROSON SCHOOL
Mumbai, India 13 - 14 December 2019

SONOANATOMY 13: Sonoanatomy of the Forearm EUROSON SCHOOL

Barcelona, Spain 23-24 January 2020

Musculoskeletal Sonography Course in Rheumatology

EUROSON SCHOOL.
Bolzano, Italy 19-21 March 2020

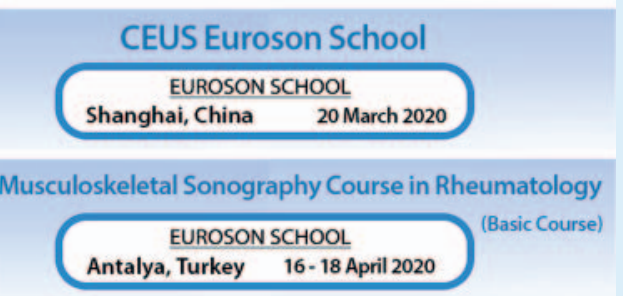

6th Euroson School for Interventional Ultrasound

EUROSON SCHOOL

Berlin, Germany $\quad 23-25$ April 2020

Musculoskeletal Sonography Course in Rheumatology EUROSON SCHOOL

Graz, Austria 6-8May 2020

\section{London CEUS Ultrasound Course}

EUROSON SCHOOL

London, UK 22-23 June 2020

\section{Chest Ultrasound Course (Advanced Course)} EUROSON SCHOOL

Košice, Slovakia 24-27 September 2020

International Course in Contrast Enhanced Ultrasound Hepatic and Extrahepatic Indications

\section{EUROSON SCHOOL}

Munich, Germany $14-17$ October 2020 


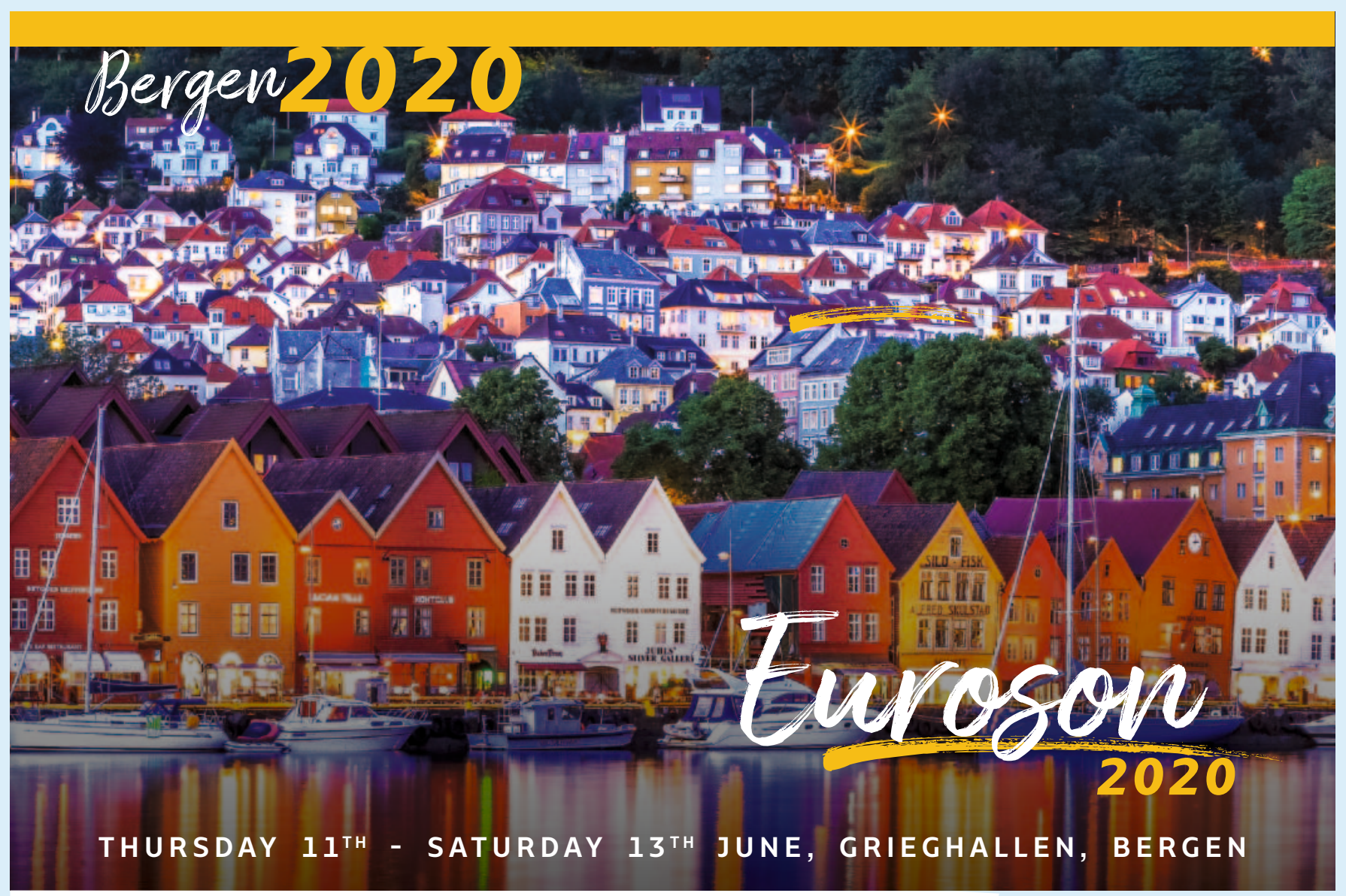

Dear colleagues,

We cordially invite you to Euroson 2020 taking place in Bergen, the gateway to the fjords and mountains of Norway. Bergen is a historic city beautifully located along the western coastline with a pulsating harbor surrounded by 7 mountains.

The venue of the congress is Grieghallen, named after Norway's famous composer Edvard Grieg, who was born and lived in Bergen. The congress is organized by the National Centre for Ultrasound in Gastroenterology and Norwegian Society for Diagnostic Ultrasound (NFUD), and this event will be NFUD's 44th conference.

Welcome to the 32nd Euroson Congress in Bergen, 11 - 13 June, 2020

Visit euroson2020.org for more information.
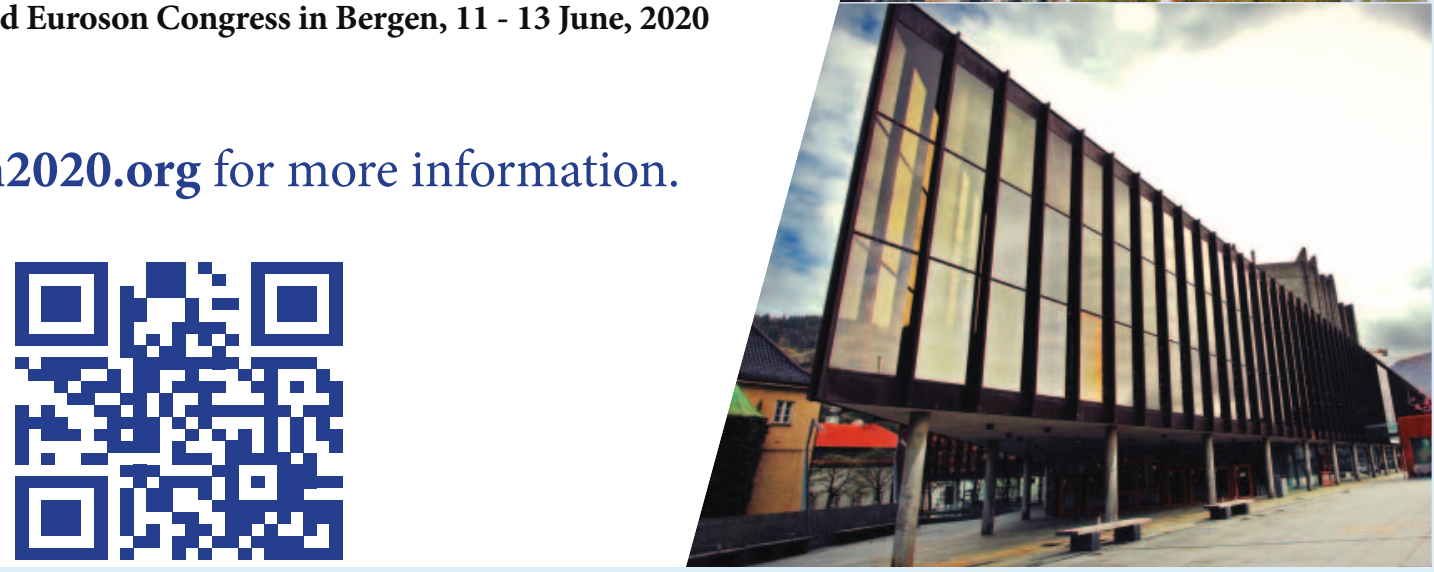


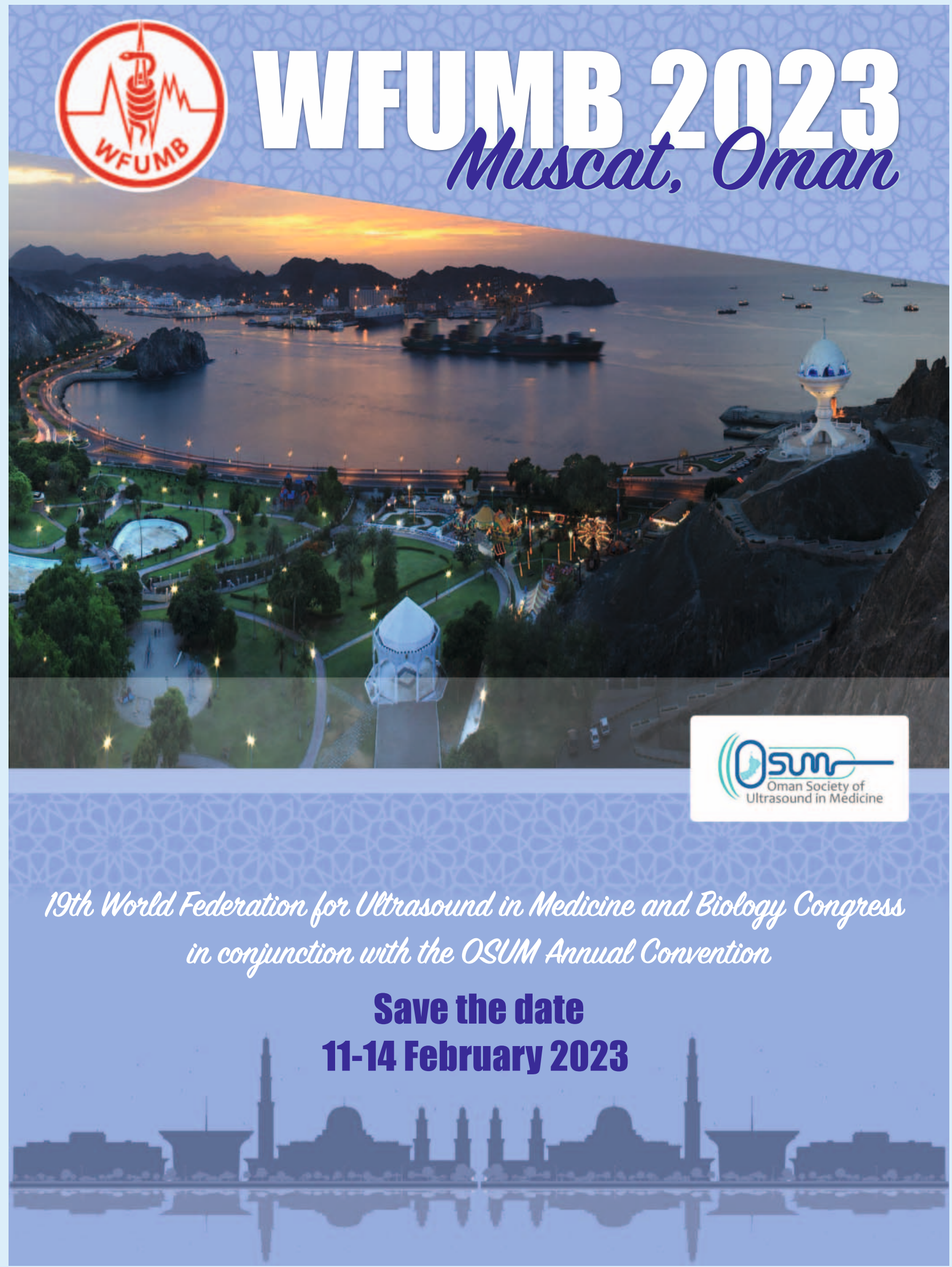

